\title{
Chemoenzymatic preparation of intermediates for the taxol side chain and analogs
}

\author{
BIMAL K. BANIK ${ }^{1}$, MAHIMA NEGI ${ }^{2}$, MAGHAR S. MANHAS ${ }^{2}$ and AJAY K. BOSE ${ }^{2}$ \\ ${ }^{1}$ The University of Texas Pan American, Department of Chemistry, Edinburg, TX 78539; \\ ${ }^{2}$ Department of Chemistry and Chemical Biology, Stevens Institute of Technology, Hoboken, NJ 07030, USA
}

Received August 11, 2009; Accepted December 21, 2009

DOI: 10.3892/mmr_00000258

\begin{abstract}
In the present study, optically active cis and trans $\alpha$-hydroxy- $\beta$-lactams were prepared by Baker's yeast reduction of a racemic $\alpha$-keto- $\beta$-lactam and by the hydrolysis of a racemic $\alpha$-acetoxy $\beta$-lactam with the resting cells of Bacillus Subtilis.
\end{abstract}

\section{Introduction}

Semi-synthetic taxol and its analogs, such as taxotere, have received significant attention from medicinal and synthetical chemists (1). Taxol and taxotere are well-known anticancer drugs (1). The side chains for these compounds can be derived from $\alpha$-hydroxy- $\beta$-lactams (2). In the present study, we describe findings from our chemoenzymatic approaches to optically pure 3-hydroxy-4-phenyl-azetidinones.

\section{Materials and methods}

Acetoxy $\beta$-lactam, 3-keto $\beta$-lactam, Baker's yeast (Saccharamyces Cerevisiae, type 3), sodium hydroxide, acetic anhydride, pyridine, methanol, p-toluenesulfonyl chloride, DMSO, Bacillus Subtilis.

\section{Results}

Reduction of $\alpha$-keto- $\beta$-lactam $(1,3)$ with Baker's yeast (Saccharamyces Cerevisiae, type 3) with methanol as the energy source produced a mixture of two $\alpha$-lactams ( 2 and 3 ) in a 3:1 ratio in an overall yield of $50 \%$ (Scheme 1). Proton NMR studies showed that 2 was a cis $\beta$-lactam and 3 was its trans isomer. The corresponding acetates 4 and 5 were studied by proton NMR spectroscopy using an optically active shift reagent, and it was found that the cis isomer 4 was of low optical purity (ee 25\%), while the trans isomer was optically pure. We have prepared by a chemical sequence the cis

Correspondence to: Dr Bimal K. Banik, The University of Texas Pan American, Department of Chemistry, 1201 West University Drive, Edinburg, TX 78539, USA

E-mail: banik@panam.edu

Key words: chemoenzymatic reaction, $\beta$-lactams, taxol side chain, anticancer agents (-)-1-(p-anisyl)-3-hydroxy-4-phenyl-2-azetidinone of a known absolute configuration, as shown by the stereostructure 6 (4). The corresponding tosylate 7 was subjected to an SN2 reaction with sodium acetate in DMSO solution to obtain the trans $\alpha$-acetoxy- $\beta$-lactam 8 (Scheme 2 ). Saponification provided the trans $\alpha$-hydroxy- $\beta$-lactam of stereostructure 9 . The yeast reduction of product 3 was found to be identical with 9 in all respects, thereby establishing its absolute configuration as in 3 . The racemic form of 12 has been synthesized recently as an intermediate for taxol analogs (1).

Acylation of a racemic alcohol and the deacylation of a racemic ester under the influence of a lipase or a microorganism are biotransformations that can lead to compounds of high optical purity (5). Sih et al reported that certain lipases are capable of acetylating alcohol groups using vinyl acetate as the acyl donor (5). After preliminary experiments, we discovered that Bacillus Subtilis can be utilized for the enzymatic hydrolysis of the acetoxyl group in 10. Thus, $50 \mathrm{mg}$ of 10 (Ar, para anisyl) in tetrahydrofuran solution was added to a suspension of Bacillus Subtilis in a phosphate buffer of $\mathrm{pH}$ 7.0. After $96 \mathrm{~h}$, the cells were removed by centrifugation and the supernatant was worked up in the usual way. Chromatography of the organic fraction over a silica gel column provided an $\alpha$-hydroxy- $\beta$-lactam 11 in $42 \%$ yield and the starting acetate 4 in $40 \%$ yield. To facilitate comparison, 11 was converted to the acetate 12 , and 4 was saponified to 2 (Scheme 3). Proton NMR studies using chiral shift reagent $\operatorname{Pr}(\mathrm{hfc})_{3}$ indicated that 12 and 4 were optically pure and were the antipodes of each other (6).

\section{Discussion}

The use of non-aqueous media for enzymatic reactions has become the subject of study for the preparation of optically active compounds from readily available racemic substrates (7-11). Optically pure cis and trans- $\beta$-lactams that are present in taxol can be prepared in this way, making the method very useful. The chemoenzymatic methods described here should be applicable to 3-hydroxy- or 3-keto-2-azetidinones with various aryl groups at positions 1 and 4 . In view of our recent work on the synthesis and biological evaluation of anticancer $\beta$-lactams, this method of enzymatic hydrolysis of the acetoxy-group and the reduction of the keto-group should prove useful (12-14). 
<smiles>O=C1C(=O)N([AlH2])[C@H]1c1ccccc1</smiles><smiles>[R6][C@H]1C(=O)N([Y1])[C@H]1c1ccccc1</smiles>
$+$

$( \pm)-1$ $\mathrm{Ar}=p$-anisyl

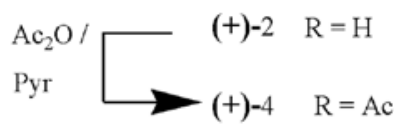<smiles>[R6][C@@H]1C(=O)N([AlH2])[C@@H]1c1ccccc1</smiles>
$20 \%$

Scheme 1.

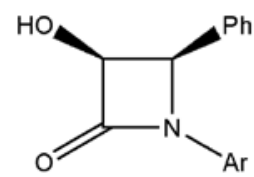

$(-)-6$

$\mathrm{Ar}=p$-anisyl
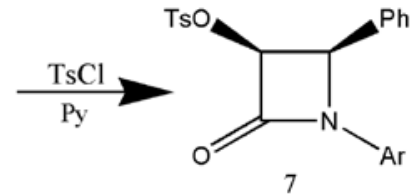
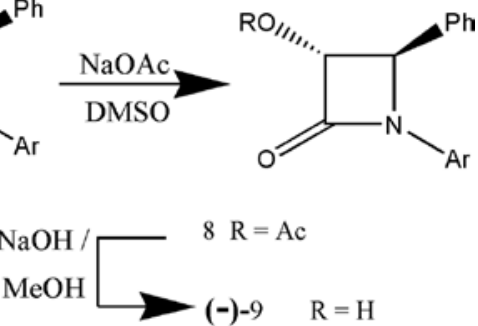

Scheme 2.

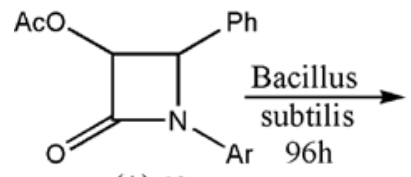

$( \pm)-10$
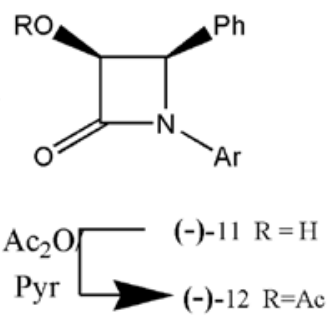

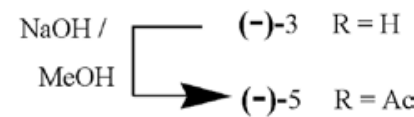

Scheme 3 .

\section{Acknowledgements}

B.K.B. gratefully acknowledges the financial support for this project from NIH-SCORE 2S06M008038-38. This research is also supported by the Howard Hughes Medical Institute (A.K.B.).

\section{References}

1. Taxol Science and Applications. Suffness M (ed.). CRC Press, Boca Raton, FL, 1995.

2. Ojima I, Habus I, Zhao M, Georg GI and Jayasinghe LR: Efficient and practical asymmetric synthesis of the taxol C-13 side chain N-benzoyl-(2R,3S)-3-phenylisoserine and its analogs via chiral 3-hydroxy-4-aryl- $\beta$-lactams through chiral ester enolate-imine cyclocondensation. J Org Chem 56: 1681-1683, 1991.

3. Van der Veen JM, Bari S, Krishnan L, Manhas MS and Bose AK: Studies on lactams. 84. Synthesis of azetidine-2, 3-diones ( $\alpha$-keto- $\beta$-lactams) via 3-(phenylthio)-2-azetidinones: J Org Chem 54: 5758-5762, 1989.

4. Banik BK, Manhas MS and Bose BK: Enantiopure $\alpha$-hydroxy$\beta$-lactams via stereoselective glycosylation. Tetrahedron Lett 38: 5077-5080, 1997.

5. Brieva R, Grich JA and Sih CJ: Chemoenzymic synthesis of the C-13 side chain of taxol: optically active 3-hydroxy-4-phenyl beta-lactam derivatives. J Org Chem 58: 1068-1075, 1993.
7. Negi M, Subbaraju GV, Manhas MS and Bose AK: Preparation of both enantiomers of an $\alpha$-hydroxy ketone via biocatalytic reduction and chemical oxidation. Enzyme Microb Technol 15: 483-488, 1993.

8. Forro E, Paal T, Tasnadi G and Fulop F: A new route to enantiopure $\beta$-aryl-substituted $\beta$-amino acids and 4-aryl-substituted $\beta$-lactams through lipase-catalyzed enantioselective ring cleavage of $\beta$-lactams. Adv Synth Catal 348: 917-923, 2006.

9. Liljeblad A and Kanerva L: Biocatalysis as a profound tool in the preparation of highly enantiopure $\beta$-amino acids. Tetrahedron 62 : 5831-5854, 2006.

10. Li XG, Lahitie M, Paivio M and Kanerva LT: Enantioselective acylation of alcohols with fluorinated $\beta$-phenyl- $\beta$-lactams in the presence of Burkholderia cepacia lipase. Tetrahedron Asymmetry 18: 1567-1579, 2007.

11. Li XG and Kanerva LT: Chemoenzymatic preparation of fluorinesubstituted $\beta$-lactam enantiomers exploiting Burkholderia cepacia lipase. Tetrahedron Asymmetry 18: 2468-2472, 2007.

12. Banik I, Becker FF and Banik BK: Stereoselective synthesis of $\beta$-lactams with polyaromatic imines: entry to new and novel anticancer agents. J Med Chem 46: 12-15, 2003.

13. Banik BK, Becker F and Banik I: Synthesis of anticancer $\beta$-lactams: mechanism of action. Bioorg Med Chem 12: 2523-2528, 2004.

14. Banik BK, Banik I and Becker FF: Stereocontrolled synthesis of anticancer $\beta$-lactams via the Staudinger reaction. Bioorg Med Chem 13: 3611-3622, 2005. 